\title{
SENI MENERJEMAHKAN PUISI: STUDI KASUS TERJEMAHAN ARAB ATAS DUA SAJAK KARYA SAPARDI DJOKO DAMONO OLEH USMAN ARRUMY
}

\author{
AKMALIYAH* \\ akmaliyah@uinsgd.ac.id \\ ASEP SUPIANUDIN* \\ asepsupianudin@uinsgd.ac.id \\ LAELY MAULIDYAH* \\ laelyattirmidzi88@yahoo.co.id \\ *Fakultas Adab dan Humaniora UIN Sunan Gunung Djati Bandung
}

\begin{abstract}
ABSTRAK
Diksi yang tertuang dalam sebuah sajak adalah hasil reproduksi amanah yang akan disampaikan kepada pembaca. Karena terdapat makna yang tersirat dalam sebuah sajak perlu adanya interpretasi agar terjaga maksud dari pengarangnya. Buku antologi puisi yang berjudul Hammuka Daaimun merupakan kumpulan dari beberapa antologi karya Sapardi Djoko Damono yang telah diterjemahkan ke dalam bahasa Arab. Buku antologi tersebut telah diterbitkan di Mesir pada tahun 2016 oleh seorang penerjemah yang bernama Usman Arrumy. Penelitian ini bertujuan untuk mengetahui teknik dan metode yang digunakan oleh penerjemah dalam antologi puisi Hammuka Daaimun tersebut. Metode yang digunakan dalam penelitian ini adalah metode kualitatif dengan cara mendeskripsikan data berupa, kata, frasa, klausa, dan kalimat. Sumber data yang digunakan dalam penelitian ini ialah buku antologi puisi Hujan di Bulan Juni (tahun) dan Melipat Jarak (tahun) karya Sapardi Djoko Damono dan buku Hammuka Daaimun karya Usman Arrumy. Berdasarkan hasil penelitian yang telah dilakukan menunjukkan bahwa, terdapat 10 teknik yang digunakan oleh penerjemah dalam menerjemahkan antologi puisi Hammuka Daaimun. Dari 10 teknik yang digunakan dalam data tersebut, terdapat 5 metode penerjemahan yang digunakan, yaitu 3 motode penerjemahan mengacu pada bahasa sumber dan 2 metode penerjemahan mengacu pada bahasa sasaran.
\end{abstract}

Kata Kunci: Penerjemahan Puisi, Teknik Penerjemahan, Metode Penerjemahan, Hujan Bulan Juni, Melipat Jarak, Hammuka Daaimun.

\begin{abstract}
A poem is one of literary works that contained an implied meaning. Therefore, it is necessary to interpret it, so that we can fully understand what e poem means. The poetry anthology book entitled Hammuka Daaimun is a collection of Sapardi Djoko Damono's anthologies that have been translated into Arabic. The anthology book was published in Egypt in 2016 by a translator named Usman Arrumy. This study aims to determine the techniques and methods used by the translator in the poetry anthology of Hammuka Daaimun. The method used in this research is a qualitative method by describing the data in the form of words, phrases, clauses, and sentences. Sources of data used in this research are the anthology of the poetry Hujan di Bulan Juni (1994) and Melipat Jarak (2015) by Sapardi Djoko Damono, and Hammuka Daaimun by Usman Arrumy. Based on the results of the research, it shows that, there are 10 techniques used by the translator in translating Hammuka Daaimun. Of the 10 techniques used in the data, there are 5 translation methods used, namely 3 translation methods referring to the source language and 2 translation methods referring to the target language.
\end{abstract}

Keywords: Poetry Translation, Translation Techniques, Translation Methods, Hujan Bulan Juni, Melipat Jarak, Hammuka Daaimun. 


\section{PENDAHULUAN}

Setiap bahasa memiliki gagasan dan pikiran, dan setiap bangsa memiliki bahasa yang berbeda. Maka, penerjemahan menjadi alat komunikasi untuk memahami kekhasan bahasa suatu bangsa tersebut serta untuk memahami pikiran dan gagasan di dalamnya (Akmaliyah, 2016, hal. 125, 2017, hal. 1). Selain itu, setiap bangsa memiliki kebudayaan yang berbeda dengan bangsa lain. Menurut Majid (dalam Syihabuddin, 2005, hal. 1), kebudayaan tidak lahir dari kekosongan. Ia didahului oleh kebudayaankebudayaan lain yang menjadi unsur pembentuknya. Kebudayaan suatu bangsa merupakan ikhtisar dari kebudayaan sebelumnya atau seleksi dari berbagai kebudayaan lain. Dengan demikian kebudayaan dapat dipandang sebagai proses memberi dan menerima. Proses tersebut terjadi dan berkembang melalui berbagai sarana, di antaranya ialah penerjemahan.

Sapardi Djoko Damono ialah seorang sastrawan yang merintis dunia kepenyairan sejak ia berada di bangku sekolah menengah atas. Kemudian, ia melanjutkan studinya di Fakultas Sastra Universitas Gadjah Mada Yogyakarta. Pada tahun 1969, seorang pelukis yang bernama Jeihan menerbitkan buku antologi puisi yang berjudul "Dukamu Abadi" karya Sapardi Djoko Damono. Dukamu Abadi ialah buku antologi puisi yang tidak memiliki kata pengantar. Terdapat 52 halaman dan berjumlah 42 puisi (Damono, 2016).

Usman Arrumy ialah seorang sastrawan yang sempat menamatkan studinya di Al-Azhar Kairo Mesir. Ia memberikan kontribusinya dalam dunia literasi dengan menerjemahkan puisipuisi karya Sapardi Djoko Damono dalam bahasa Arab. Sebagai penerjemah, ia telah menerjemahkan 76 puisi karya Sapardi Djoko Damono.
Namun, ia tak hanya menerjemahkan puisi dari satu buku karya penulis aslinya. Beberapa karya penulis lainnya yang memuat karya yang di dalamnya terdapat puisi yang telah diterjemahkan, antara lain buku Sajak Hujan di Bulan Juni dan Melipat Jarak. Penerjemah menerjemahkan dan merangkum puisipuisi tersebut dalam buku antologi puisi yang berjudul Hammuka Daaimun. Kemudian, buku tersebut diterbitkan di Mesir pada tahun 2016. Dalam penelitian ini, peneliti akan meneliti puisi yang telah diterjemahkan ke dalam bahasa Arab sebanyak 20 buah puisi dari sumber data yang telah ditemukan. Jumlah tersebut dirasa cukup untuk mewakili buku antologi puisi Hammuka Daaimun karya Usman Arrumy. Dasar pemilihan puisi tersebut disesuaikan dengan teks bahasa sumber yang telah ditemukan.

Penerjemahan merupakan jembatan bagi suatu bangsa. Dalam kajian penerjemahan terdapat istilah yang disebut teknik dan metode menerjemahkan. Metode dan teknik ini merupakan salah satu teori dalam penerjemahan. Menurut Akmaliyah ( 2017, hal. 16), bahwa secara sempurna penerjemah dapat menerapkan teori penerjemahan, di samping mengasah keterampilannya dalam hal menerjemahkan. Keterampilannya itu dapat didukung dengan teori penerjemahan. Pada penerjemahan kalimat dari bahasa Arab ke bahasa Indonesia, misalnya tidak mutlak terpaku pada satu model dan teknik penerjemahan. Artinya, pada saat tertentu atau menurut penerjemah satu dan lainnya akan memilih model dan teknik penerjemahan yang berbeda dalam kegiatan penerjemahannya (Akmaliyah, 2016, hal. 132).

Kata teknik, menurut Kamus Besar Bahasa Indonesia online, diartikan sebagai metode atau sistem dalam 
mengerjakan sesuatu. Teknik menerjemahkan ialah cara yang digunakan untuk mengalihkan pesan dari bahasa sumber ke bahasa sasaran, yang diterapkan pada tataran kata, frasa, klausa maupun kalimat. Sedangkan metode menurut Kamus Besar Bahasa Indonesia ialah cara teratur yang digunakan untuk melaksanakan suatu pekerjaan agar tercapai sesuai dengan yang dikehendaki. Metode penerjemahan adalah orientasi yang hendak dicapai oleh penerjemah dalam terjemahannya. Adapun pendapat lain, metode penerjemahan adalah cara tertentu yang dipilih dan dipercaya oleh penerjemah untuk melaksanakan sebuah proses penerjemahan terhadap sebuah penugasan (Albir, 2002, hal. 507).

Menurut Peter Newmark, dalam bukunya yang berjudul $A$ Text book of Translation (1988), metode penerjemahan terbagi menjadi dua, yaitu berdasarkan acuan bahasa sumber dan sasaran. Metode penerjemahan terdiri dari 8 metode, 4 di antaranya mengacu kepada bahasa sumber dan 4 metode lainnya mengacu kepada bahasa sasaran. Berikut adalah metode penerjemahan yang mengacu pada bahasa sumber, antara lain metode kata per kata, harfiyah, setia, dan semantik. Adapun metode penerjemahan yang mengacu pada bahasa sasaran, antara lain metode adaptasi, bebas, idiomatik, dan komunikatif (Syihabuddin, 2005, hal. 71-72).

Penelitian ini merupakan bentuk aplikasi dari teori teknik dan metode menerjemahkan dalam buku Antologi Puisi Hammuka Daaimun oleh Usman Arrumy. Pada dasarnya, motode penerjemahan mengarahkan penerjemah dalam memilih teknik penerjemahan.

\section{METODE}

Analisis data dilakukan dengan metode deskriptif kualitatif. Penelitian deskriptif melibatkan kumpulan teknik yang digunakan untuk menentukan, menggambarkan, atau menggambarkan fenomena yang terjadi secara alami tanpa manipulasi eksperimental. Penelitian kualitatif adalah jenis penelitian yang bertumpu pada data tidak terstruktur dan nonnumerik. Menurut Cresswell dalam Azizah (2019, hal. 37), studi kualitatif sebagai suatu proses inkuiri untuk memahami suatu masalah sosial atau manusia berdasarkan kompleks bangunan, gambaran bersejarah, dibentuk dengan kata-kata, melaporkan ulasan rinci responden dan dilakukan dalam suasana alam.

Penelitian kualitatif cenderung menganalisis data secara induktif. Proses induktif dapat menemukan fakta seperti yang tercakup dalam data. Penelitian kualitatif meliputi studi penggunaan dan kompilasi berbagai materi empiris yang berupa studi kasus, pengalaman pribadi, introspektif, kisah hidup, sejarah, interaksional, dan teks visual yang menjelaskan makna dan momen rutin dan problematis dalam kehidupan individu (Suparman, 2009, hal. 24). Dalam tulisan ini, dua sajak Sapardi Djoko Damono yang telah diterjemahkan ke dalam Bahasa Arab oleh Usman Arrumy menjadi data utama untuk menemukan metode dan teknik penerjemahan.

\section{HASIL DAN PEMBAHASAN}

Teknik menurut Collins English Dictionary (dalam Machali, 2000, hal. 77), a technique is a practical method, skill, or art applied to a particular task, artinya teknik adalah suatu metode, keahlian atau seni praktis yang diterapkan pada suatu tugas tertentu. Dalam definisi tersebut terdapat dua hal 
penting: yang pertama, teknik ialah hal yang bersifat praktis; dan yang kedua, teknik diberlakukan terhadap tugas tertentu (dalam hal ini tugas penerjemahan). Istilah teknik, menurut Newmark merujuk pada proses penerjemahan kalimat dan unit-unit terjemah yang lebih kecil, sedangkan metode mengacu pada proses penerjemahan secara keseluruhan. Dengan kata lain, teknik menerjemahkan terkait dengan penanganan teks pada tataran mikro. Objek metode penerjemahan adalah wacana. Sedangkan objek teknik menerjemahkan berupa kalimat yang notabene merupakan unit paling kecil dalam ranah sintaksis (Farisi, 2011, hal. 60).

Menurut Molina Albir, teknik penerjemahan memiliki lima karakteristik, yaitu: teknik penerjemahan memengaruhi hasil terjemahan, teknik diklasifikasikan dengan perbandingan pada teks bahasa sumber, teknik berada pada tataran mikro, teknik tidak saling berkaitan tetapi berdasarkan konteks tertentu, dan teknik bersifat fungsional (Albir, 2002, hal. 498-512). Lebih lanjut Albir menjelaskan bahwa terdapat 18 teknik menerjemahkan, ialah sebagai berikut: adaptasi, peminjaman, implikasi, reduksi, kalke, kreasi diskursi, kompensasi, deskripsi, padanan lazim, generalisasi, amplifikasi linguistik, kompresi linguistik, penerjemah harfiyah, modulasi, partikularisasi, substitusi, transposisis, dan variasi (Albir, 2002).

Dalam penerjemahan, disamping teknik, ada pula metode penerjemahan. Kata metode berasal dari kata method dalam bahasa Inggris. Menurut Macquari Dictionary dalam (Rochayah Machali, 2000: 48), a method is a way of doing something, especially in accordance with a definite plan, artinya metode adalah suatu cara melakukan sesuatu, terutama yang berkenaan dengan rencana tertentu. Menurut Molina dan Albir (dalam Farisi, 2011, hal. 51), translation method refers to the way of particular translation process that is cerried out in terms of the translator's objective, artinya metode penerjemahan merujuk pada cara tertentu yang digunakan dalam proses penerjemahan sesuai dengan tujuan penerjemahan. Misalnya, sebuah opsi global penerjemah yang memengaruhi keseluruhan teks. Sementara menurut Newmark dalam bukunya yang berjudul $A$ Text book of Translation (1988, hal. 45-47), dijelaskan bahwa terdapat dua kategori metode penerjemahan yang menurut peneliti tepat dalam proses kegiatan penerjemahan, yaitu berdasarkan kepada bahasa sumber dan berdasarkan bahasa sasaran, yang semuanya terbagi menjadi delapan metode penerjemahan. Berikut di bawah ini adalah bagan metode penerjemahan berdasarkan pada penekanannya.

\begin{tabular}{|l|l|}
$\begin{array}{l}\text { Penekanan } \\
\text { pada Bahasa } \\
\text { Sumber }\end{array}$ & $\begin{array}{l}\text { Penekanan pada } \\
\text { Bahasa Sasaran }\end{array}$ \\
\hline $\begin{array}{l}\text { Metode kata } \\
\text { demi kata }\end{array}$ & Metode adaptasi \\
\hline Metode harfiah & Metode bebas \\
\hline Metode setia & Metode idiomatik \\
\hline $\begin{array}{l}\text { Metode } \\
\text { semantik }\end{array}$ & Metode kumunikatif \\
\hline
\end{tabular}

Dengan demikian, metode penerjemahan sangat memengaruhi hasil terjemahan. Maksudnya, hasil terjemahan teks sangat ditentukan oleh metode penerjemahan yang dipakai oleh penerjemah karena maksud, tujuan, dan kehendak penerjemah akan berpengaruh terhadap hasil terjemahan secara keseluruhan. Hal tersebut dipertegas oleh pendapat Newmark (dalam Hartono, 2009, hal. 17) yang menyatakan: "while translation methods 
relate to whole texts, translation procedures are used for sentences and the smaller units of language". Dari beberapa pendapat di atas dapat disimpulkan dua hal pokok mengenai metode, yaitu cara tertentu penerjemahan dan rencana dalam pelaksanaan penerjemahan. Dalam hal menerjemahkan naskah terdapat rencana penerjemahan yang harus melewati 3 tahap, yaitu analisis, pengalihan, dan penyerasian.

Dalam buku antologi Hammuka Daimun, penerjemah lebih mendominasi menggunakan metode penerjemahan adaptasi. Data tersebut dapat ditemukan dalam puisi yang berjudul "Pintu".

Pintu
Pagi dikaruniai begitu banyak pintu
dan kita disilahkan masuk
melewatinya kapan saja.
Malam diberkahi begitu banyak
gerbang dan kita digoda untuk
membukanya dan keluar agar bisa ke
sana.
Tidak diperlukan ketukan.
Tidak diperlukan kunci.
:
Sungguh, tidak diperlukan selamat
datang atau selamat tinggal
amono, 2015, hal. 110).

Teks puisi tersebut telah diterjemahkan ke dalam bahasa Arab, sebagai berikut:

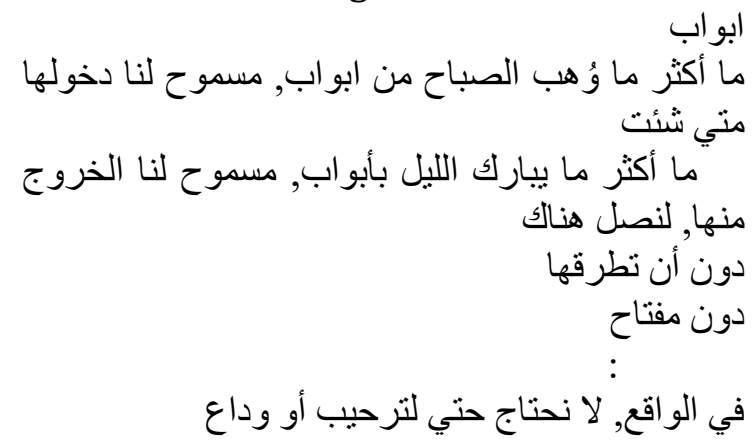

(Arrumy, 2016, hal. 72)
Dari pemaparan data di atas, puisi yang berjudul "pintu" dapat dianalisis sebagai berikut:

Kata "pintu" dalam kaidah bahasa sumber yaitu bahasa Indonesia menunjukkan makna tunggal, akan tetapi ketika diterjemahkan ke dalam bahasa Arab, kata "pintu" tersebut menjadi bentuk jamak yaitu "أبواب". Penggunaan kata bermakna jamak dalam bahasa sasaran dirasa tepat menurut penerjemah, sehingga penerjemah mengadaptasi struktur gramatikal bahasa sasaran. Teknik penerjemahan yang digunakan dalam data tersebut ialah teknik menerjemahkan modulasi.

Kemudian, pada kata "pagi" dalam puisi tersebut merupakan kata pertama yang terletak pada bait pertama, namun ketika kata "pagi" tersebut diterjemahkan menjadi "الصباح". Penerjemah meletakkan kata tersebut tidak lagi pada awal kalimat dalam penerjemahan bahasa Arab. Penerjemah berusaha mengubah kultur bahasa sumber ke dalam bahasa sasaran. Dari data tersebut dapat diketahui bahwa teknik yang digunakan penerjemah ialah teknik kalke, karena mempertahankan struktur bahasa sasaran seakan-akan menampilkan sesuatu yang baru.

Kata selanjutnya, ialah kata "begitu banyak" yang terdapat pada bait pertama dan kedua. Ungkapan tersebut merupakan ungkapan yang menunjukkan kuantitas sesuatu namun ketika diterjemahakan ke dalam bahasa Arab menjadi "اكثر ما". Dalam gramatikal bahasa sasaran, kata tersebut memiliki kaidah "أفعل ما" yang mana bentuk tersebut menunjukkan makna taajjub atau menunjukkan makna keheranan. Data tersebut menunjukkan bahwa penerjemah menggunakan teknik modulasi. 
Hal tersebut merupakan fakta yang mendorong peneliti untuk melakukan penelitian yang berjudul "Teknik dan Metode Menerjemahkan Indonesia-Arab pada Antologi Puisi Hammuka Daimun oleh Usman Arrumy (Kajian Penerjemahan).

No Bahasa Sumber Bahasa Sasaran

1 Berikut puisi Berikut puisi yang berjudul tersebut yang "Sepatu" telah terdapat dalam diterjemahkan buku Melipat ke dalam Bahasa Jarak halaman Arab oleh Usman 23: $\quad$ Arrumy yang terdapat di dalam buku

Sepatu antologi

Kau tak merasa Hammuka sepatumu telah Daaimun menginjak halaman 29. Kerikil dan الحذاء لا لتشعر أن حذائك داس daun tua di jalan kecil itu;

Kau tak الحصي ذو و الورق المسين"في ذالك الطريق pembicaraan

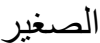
yang bijak

Antara daun dan kerikil itu tentang sepatumu

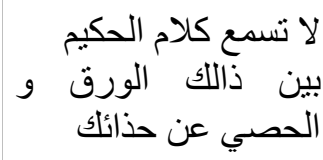

Berikut analisis puisi yang berjudul "Sepatu".

\begin{tabular}{|c|c|}
\hline $\begin{array}{r}\text { Bahasa Sasaran } \\
\text { (Bsa) }\end{array}$ & Bahasa Sumber (Bsu) \\
\hline لا تشعر & Kau tak merasakan \\
\hline أن حذائك داس & $\begin{array}{l}\text { Sepatumu telah } \\
\text { menginjak }\end{array}$ \\
\hline الحصي & Kerikil \\
\hline 9 & Dan \\
\hline الورق المسن & Daun yang tua \\
\hline في فير ذالك الطريق & Di jalan kecil itu \\
\hline
\end{tabular}

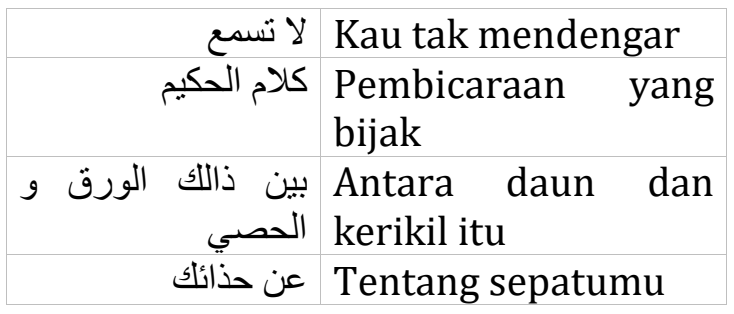

Dari tabel di atas, disimpulkan bahwa teknik penerjemahan yang digunakan oleh penerjemah ialah teknik penerjemahan harfiah. Penerjemah menerjemahkan sesuai dengan diksi dalam setiap baris puisi tersebut dan penempatan hasil terjemahan pun sesuai dengan bahasa sasaran. Adapun metode penerjemahan yang digunakan pada puisi tersebut ialah metode penerjemahan harfiah, yaitu yang mengacu pada bahasa sumber.

\section{KESIMPULAN}

Puisi adalah perwujudan peristiwaperistiwa dalam struktur ruang dan waktu yang baru, yang dipadatkan lewat kata-kata. Puisi merupakan representasi dunia dalam kata; suatu realitas konteks yang diserap dan dibangun kembali ke dalam realitas teks. Puisi, bahkan dalam beberapa aspeknya, mampu merepresentasikan kemasalaluan dalam struktur dan makna yang baru, sehingga memungkinkannya untuk tetap hadir sebagai bentuk penyeimbang estetis kehidupan manusia dalam realitas sosialnya. Hal ini menjadi mungkin karena puisi adalah karya seni yang lahir dari rahim kebudayaan dan realitas sosial manusia itu sendiri; bahwa terdapat hubungan kongkrit antara seni sebagai tindakan individual dan struktur sosial yang melingkupinya. Oleh karena itu, puisi sebagai bentuk karya seni sastra adalah sebuah produk yang, dalam beberapa hal, terkondisikan oleh kehidupan sosial. 
Menerjemahkan puisi dengan demikian adalah proses yang tidak hanya berkutat dengan dua bahasa yang berbeda, akan tetapi lebih jauh dari itu juga adalah menerjemahkan rasa, ruang dan waktu, serta konstruksi realitas yang jalin menjalin hadir di dalam teks. Pada akhirnya, menerjemahkan puisi adalah suatu seni tersendiri yang memerlukan rasa kepenyairan yang cukup mumpuni, dan di sini, Usman Arrumy telah cukup berhasil menggunakan beberapa teknik dan metode penerjemahan dan menyajikan kepada pembaca berbahasa Arab bukan sekadar teks terjemahan tetapi juga melingkupi rasa sastra yang bagus. Dari sajak yang dianalisis diatas, terdapat 10 teknik yang digunakan oleh penerjemah dalam menerjemahkan antologi puisi Hammuka Daaimun, ialah: modulasi, amplikasi, harfiyah, reduksi, kalke, transposisi, adaptasi, deskripsi, generalisasi, dan borrowing. Dari 10 teknik yang digunakan dalam data tersebut, terdapat 5 metode penerjemahan yang digunakan, yaitu 3 motode penerjemahan mengacu pada bahasa sumber dan 2 metode penerjemahan mengacu pada bahasa sasaran.

\section{DAFTAR PUSTAKA}

Akmaliyah. (2016). Model dan Teknik Penerjemahan Kalimat Bahasa Arab Ke Dalam Bahasa Indonesia. AlTsaqafa, 13, No. 1, 125-134. https://doi.org/10.15575/altsaqafa.v13i01.1836
Akmaliyah. (2017). Teori dan Praktik Terjemah Indonesia-Arab. Kencana.

Albir, L. M. A. (2002). Translation techniques revisited: A dynamic and functionalist approach. Meta: Translators' Journal, XLVII(4).

Arrumy, U. (2016). Hammuka Daaimun. Dar Tweeta.

Azizah, F. N. (2019). The Lexical Relation in Surah Arrahman in The Holy Quran Translation by Muhammad Mukhsin Khan. Bandung. UIN Sunan Gunung Djati Bandung.

Damono, S. D. (2015). Melipat Jarak. PT Gramedia Pustaka Utama.

Farisi, Z. Al. (2011). Pedoman Penerjemahan Arab-Indonesia. PT Remaja Rosdakarya.

Hartono, R. (2009). Teori Penerjemahan. CV. Cipta Prima Nusantara.

Machali, R. (2000). Pedoman Bagi Penerjemah. Grasindo.

Newmark, P. (1988). A Textbook of Translation. Prentice-Hall International.

Suparman, U. (2009). Qualitative Research for Language Teaching and Learning. Arfino Raya.

Syihabuddin. (2005). Penerjemahan Arab Indonesia. Humaniora. 